\title{
Study on the infiltration of academy culture into local folk custom
}

\author{
YiXiaohui, LiuYuehua \\ Nanchang Institute of Science \& Technology, Nanchang 330108,China
}

\begin{abstract}
Key words: academy culture; lower than folk custom; osmosis; Xianghu culture; Yuelu Academy
\end{abstract}

\begin{abstract}
By tracing the origin and evolution of Chinese Academy Culture, this paper analyzes the function of academy culture and its influence on local politics and culture, and reveals the osmosis of academy culture to the folk custom. This paper reveals local academy characteristics by the Bailudong academy school regulations, and reveals the influence of academy culture on local customs by the political function of the academy, such as Confucian political benefit the local people to get rid of disadvantages. Finally, with the influence of Yuelu Academy on local culture in Xianghu, we get some conclusions about the influence of academy culture on local characteristic culture. The unique cultural character has been bred by Huxiang culture, Yuelu Academy has shown this personality to perfection, the college has developed the country Master instruments and patriotic soldiers who saved the nation, they have the national spirit of Xianghu culture and are deeply influenced by Yuelu Academy. This influence and spirit continue to this day, and it is an important embodiment of academy culture which is lower than the folk custom.
\end{abstract}

\section{Introduction}

Academy is a unique form of educational organization in ancient china, it was founded in the Tang Dynasty, developed in the Five Dynasties, flourished in the Song Dynasty, and continued to rise and fall in the Yuan, Ming and Qing Dynasties. It existed for thousands of years in Chinese history, academy culture has profound influence on the development of Chinese national politics, economy and culture, especially on the local folk custom. Take Xianghu culture as an example, Yuelu Academy has made a very important share for the unique college education model of Xianghu culture, and the academy culture is the gem of the local characteristic culture development. At present, it is of great practical significance to study the academy culture and analyze the cultural value of the times, and it is also of great practical significance for the construction of a distinctive society, the main culture and the promotion of the cultural soft power.

\section{The origin and development of academy culture}

The Academy first appeared in the Tang Dynasty, which is due to the abolition of the selection of personnel "Pizhen" and "township election and recommendation " formulation and implementation of the imperial examination system in the Sui and Tang Dynasties, the examination methods was used in the appointment and selection of personnel, which produced the Academy. The Academy was only a prototype in the Tang Dynasty, and there were two different uses in the course of its development, one kind is specially prepares for the imperial examination, pays great attention to the poetry, specially deals with the article and the poetry in the imperial examination system; The second use is temporary buildings in the mountains and woods, for scholars and bachelors together to chat, talk about poetry, focusing on rest and entertainment. Bailudong academy is a typical second kind of academy, the academy was built by Zhu Xi, a former recluse of Li Bo's study site, 
because once again raised a white deer, so it has been named the Bailudong academy.

In the Song Dynasty, academies began to grow, showing their changes in scale, function and nature. These changes were closely related to the rise of Neo Confucianism, and this Neo Confucianism was the new Confucianism at that time. During the Northern Song Dynasty, Confucianism began to revive, under the impetus of a group of new Confucianism thinkers and educationists, the Confucian classics culture began to rise in various parts of the country, and thus established a variety of local academy. Fan Zhongyan was a famous statesman of the Song Dynasty, he set up a new government position in politics, and arose the wind of lecturing, the new Confucian movement has been more long-term development. During the Northern Song Dynasty, the status of Neo Confucianism became higher and higher, and finally a clear geographical school was formed, for example, "Shu Xue" of Su Shi and his son, "Lian Xue" of Zhou Dunyi, and so on. Moreover, the local colleges corresponding to these schools have been formed, which are obviously different from Buddhism and monasteries. These academies are still the main contents of Confucian culture and become an important position for the revival of confucianism.

After the Song Dynasty and the Ming Dynasty, academy culture developed vigorously, and this period was the most prosperous period of history, culture and education in china. In the Yuan Dynasty, the Academy began to pay more attention to the imperial examination, and is committed to research and develop "the Four Books and the Five Classics", and the standards and norms of examination have been established by Academy, however, the popularity of education has been greatly improved. Because some colleges perform well in places, authorized by the Emperor, and get the national treasury's appropriate funds. However, these colleges did not have unified standards and institutions at first, and they all belonged to the form of private universities or colleges in the form.

\section{The basic connotation of academy culture}

The development of academy culture has different characteristics in different regions, but there are also closely related places, for example, its connotation. The basic connotation of academy culture mainly consists of three parts, including seeking truth, seeking good and seeking beauty.

(1) Seeking truth

Seeking truth is the ascription of all academic research, the Academy aims at the Confucian culture, in a relatively relaxed academic atmosphere in college, there are a lot of academic activities, and specialized instructors engaged in the research of the truth, and the freedom of teaching, they may debate with each other, each one airs his own views. In the study, teachers encourage academic to the truth, dare to criticize, not superstitious authority, encourage students to have their own characteristics, thus greatly promoting the enthusiasm of students to learn the truth, active ability of innovative thinking and judgment, which greatly promoted the development of Confucianism in place.

(2) Seeking good

Academy culture takes Confucianism as the fundamental, so it is not only the pursuit of knowledge in the process of learning culture, but also adhere to students' virtue, persist in cultivating erudite and etiquette, erudite and resourceful, so as not to a knowledgeable but not moral.

(3) Seeking beauty

In the construction of academy environment, the ancient academy pays great attention to the choice of environment, most of the site is chosen in a clean and scenic place, which provide the necessary conditions for college students from the secular, self-cultivation, and which is the pursuit 
of "harmony" to do the groundwork. The site of the academy is surrounded by mountains and surrounded by water, on the one hand, students and teachers can explore poetry in the quiet environment, and enjoy the beautiful rivers and mountains of a country brings elegant; on the other hand, the beautiful scenery can also cultivate the teachers and students' sentiment, which laid the foundation for the realization of students' mind and inspire grand ambition, and paves the way for the students to achieve ambitions.

\section{The influence of academy culture on regional folk custom}

Academy culture has a profound influence on local folk customs, Yuelu Academy, for example, has nurtured a unique cultural personality for the development of Huxiang Culture. Chinese Academy trained a large number of talents in the Song Dynasty, the Ming Dynasty and later, and some of them were in politics. Because of the influence of academy culture, Confucianism, they got rid of many shortcomings in politics, has formulated a series of policies to be Huimin, loved by local people, became Country Squires, which made an important contribution to the stability and development of society and the social cultural value and moral support.

The unique cultural character has been bred by Huxiang culture, Yuelu Academy has shown this personality to perfection, the academy is devoted to academic research, seeking truth from facts, while learning and creative thinking, they paid attention to the pursuit of truth and did not resort to deception. This is also an important factor and a national sentiment for the local and even the whole nation to govern the country. This spirit has also been used today, on the one hand, it laid the foundation for the national patriotic spirit of local characteristics in Xianghu. On the other hand, it has reached a new level for the development of the education of scholar persons with ideals and integrities.

Since ancient times, academy culture has made an important contribution to the education of national patriotism in Xianghu area, from Zhang Ying, who defend the national interests of the army, to Patriotic officials and statesmen of the Ming and Qing Dynasties, Wang Fuzhi, Zheng Guofan, Zuo Zongtang and so on, deeply influenced by Xianghu culture, patriots such as Tan Sitong, Huang Xing, Cai E and so on, to save the nation and modern Chinese founder Mao Zedong et al. It also embodies the spiritual characteristics, they are the concentrated expression of the spiritual guidance of Yuelu Academy in Huxiang culture.

\section{Conclusion}

The origin, development and function of academy culture has been analyzed in this paper, and from the two aspects of politics and culture, the influence of academy culture on the political and cultural methods of regional folkways has been expounded in this paper. Academy culture has an important influence on the development of political Folkways in Xianghu, and has made important contributions to the education of national patriotism in Xianghu, from the ancient Zhang Shiwei to the modern Mao Zedong, the academy culture permeated the local folk custom and provided a strong patriotic spirit pillar. In the current society, the main culture construction of the social with Chinese characteristics is been carried out in full swing, the cultural soft power has become a national comprehensive national strength, it plays an important role in modern education for academy culture research.

\section{Acknowledgement}

The work was supported by the Humanities and Social Sciences project in Jiangxi with the project 
number JC1567 and the project name Study on the Infiltration of Academy Culture into Local Folk Custom.

\section{Reference}

[1] Zhang Yingqiang, Fang Hualiang. From the living space to the cultural space: How to Implement the Modern University Academy System[J]. Journal of Higher Education, Vol.37( 03), (2016), p.56-61

[2] Cui Haibo, Li Kunfeng. Summary and Thoughts of University “Academy System” in China[J]. Journal of Dali University. Vol.14(11), (2015), p.81-87

[3] Wen Xu. A new model of education and management for college students of ethnic minorities in the academy system [J]. Contemporary Youth Research. No.06, (2014), p.81-25

[4] Zhao Mingjun. On how to construct the Trinity ideological and political education model [J]. Xiang Chao, 9 (2010) , p.118-119

[5] Ji Haiju. In the micro-blog in ideological and Political Education: blocked or hand [J]. Academia Bimestrie, No.5, (2011) , p.196-200

[6] Zhang Zhongdi. Review of campus culture construction and ideological and political education in Colleges and universities. [J]. Forum on Contemporary Education,No.1, (2009), p.114-116

[7] Tao Lei, Kang Bozhou, Zhao Mingliang. Yue Art Gallery [J]. Urban Environment Design, Z2, (2013), p.204-209.

[8] Hu Guoliang. Technology and innovation in design of urban planning exhibition halls [J]. Arts in China, 07,(2010), p.128-129.

[9] Hu Guoliang, Tong Jing. Innovative analysis of exhibition space form in later times[J]. Creation and Criticism,No.7, (2015), p.104-106

[10] Huang Jiancheng. Space exhibition design [M]. Peking University press, (2013), p.80-86.

[11] Niu Menggang. Menggang inherit the ancient academy culture to strengthen the spirit of modern university culture construction [J]. Journal of Zibo Normal College, Vol.29 (3), (2012), p.19-23

[12] Jiao Aixin. Analysis of the influence of traditional architectural decoration culture on modern architectural decoration [J]. China Packaging Industry, 07, (2014), p.55-57

[13] Zhou Jingchun, Zhu Xingtao. The concept of Chinese Academy Education and Its Modern Enlightenment [J]. Modern Educational Science,No.2, (2009), p.39-44

[14] Wan Jingmin. Academy and the development of Chinese Confucian culture [J]. Library and Information Service, No.2, (2010), p.76-77,108

[15] Wang Shengjun, Deng Hongbo. Research on principl ZHANG Tu-nan of Yuelu Academy in the Yuan Dynasty [J]. University Education Science, No.01, (2011), p.85-87 